\title{
Impact of an intervention on the availability and consumption of fruits and vegetables in the workplace
}

\author{
Daniel Henrique Bandoni* , Flávio Sarno and Patricia Constante Jaime \\ Department of Nutrition, School of Public Health, University of São Paulo, Av. Dr Arnaldo 715, \\ 01246-904 São Paulo - SP, Brazil
}

Submitted 15 April 2010: Accepted 9 November 2010: First published online 21 December 2010

\begin{abstract}
Objective: To evaluate the impact of an educational and environmental intervention on the availability and consumption of fruits and vegetables in workplace cafeterias.

Design: This was a randomized intervention study involving a sample of companies that were divided into intervention and control groups. The intervention, which focused on change in the work environment, was based on an ecological model for health promotion. It involved several different aspects including menu planning, food presentation and motivational strategies to encourage the consumption of fruits and vegetables. The impact of the intervention was measured by changes (between baseline and follow-up) in the availability of fruits and vegetables that were eaten per consumer in meals and the consumption of fruits and vegetables in the workplace by workers. We also evaluated the availability of energy, macronutrients and fibre.

Settings: Companies of São Paulo, Brazil.

Subjects: Twenty-nine companies and 2510 workers.

Results: After the intervention we found an average increase in the availability of fruits and vegetables of $49 \mathrm{~g}$ in the intervention group, an increase of approximately $15 \%$, whereas the results for the control group remained practically equal to baseline levels. During the follow-up period, the intervention group also showed reduced total fat and an increase in fibre in the meals offered. The results showed a slight but still positive increase in the workers' consumption of fruits and vegetables (about $11 \mathrm{~g}$ ) in the meals offered by the companies.

Conclusions: Interventions focused on the work environment can be effective in promoting the consumption of healthy foods.
\end{abstract}

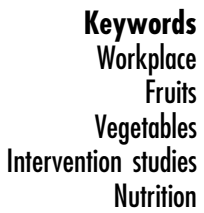

Keywords

Fruits

Vegetables

Nutrition
Studies have demonstrated that low consumption of fruits and vegetables is associated with the development of certain chronic diseases, such as CVD and diabetes ${ }^{(1-3)}$. These diseases could be mitigated through the consumption of fruits and vegetables by means of their protective constituents, such as potassium, folate, vitamins, fibre and other phenolic compounds ${ }^{(3,4)}$. Traditionally, the intake of these foods in the Brazilian population falls below recommended levels. For instance, less than half of Brazilians consume fruit on a daily basis, under one-third consume vegetables every day, and only $13 \%$ of the population consumes the recommended five servings of fruits and vegetables per day ${ }^{(5)}$.

Innovative strategies are needed to encourage greater fruit and vegetable consumption by promoting healthy habits and creating environments that promote these foods. Many effective initiatives have been utilized to promote healthy eating and the workplace is considered a good setting for interventions aimed at promoting healthy behaviour ${ }^{(6,7)}$.

Previous intervention studies have shown that changes introduced in the workplace can have a positive impact on the consumption of fruits and vegetables. Studies have employed various intervention methodologies and strategies, such as the development of healthier recipes and menus, the use of healthy food labels, educational messages, and even price reductions ${ }^{(8-11)}$.

Some published intervention studies have used ecological models and focused on environmental and structural strategies in the workplace, including workplace lunches, to achieve increased consumption of fruits and vegetables $^{(12,13)}$. The ecological model aims to identify environmental causes of behaviour because they create opportunities for intervention and remove barriers for maintaining a healthy diet ${ }^{(14)}$. Food service staff exert an important influence over food consumption through the 
menu they prepare and the ingredients they use ${ }^{(15)}$. They also play a role in facilitating the healthy choices of restaurant consumers ${ }^{(11)}$.

However, there is a lack of intervention studies in developing countries. To date, the majority of studies on this topic have been conducted in developed countries $^{(16)}$. Extrapolating the outcomes of studies carried out in developed countries can lead to equivocal conclusions when they are applied to developing countries. Factors such as working conditions, working hours and public policies differ between countries and certainly have a major influence on food consumption in the workplace. Moreover, the impact of nutritional interventions on the availability of fruits and vegetables in the workplace has rarely been investigated in Brazil, although workers' dietary habits have more commonly been assessed ${ }^{(17)}$.

Thus, the aim of the present study was to assess the impact of an educational and environmental intervention on the availability and consumption of fruits and vegetables in a sample of workplace cafeterias in the city of São Paulo, Brazil.

\section{Methodology}

\section{Study outline}

This was a randomized, controlled intervention study involving a sample of thirty companies separated into two groups (intervention and control). The intervention was based on an ecological model for health promotion programmes. The sample comprised companies enrolled in the Workers' Food Program. The Workers' Food Program is a Brazilian policy initiative that encourages companies to offer subsidized meals (with fixed prices per meal) to their employees. More than 190000 companies have enrolled in the programme and, according to data provided by the Brazilian Ministry of Labor and Employment, São Paulo has the highest participation rate with almost $30 \%$ of all companies enrolled.

To participate in the study, companies had to prepare and distribute at least 150 meals daily and be located in São Paulo. The sample size was calculated based on the goal of identifying an increase of at least $10 \%$ in the availability of fruits and vegetables at lunch (per consumer), with a 95\% confidence interval and 90\% statistical power. The acceptance rate for participation in the study was $42 \%$ (of the seventy-one companies invited, thirty agreed to participate).

The companies enrolled in the study were stratified by the number of meals offered daily (150-250, 251-500, 501-700 and >700 meals/d) and randomly split into either the intervention or the control group. All companies selected for the study were from the private sector.

After placing the companies in either the intervention or control group, all workers at the companies were invited to participate in the study. Those workers who agreed voluntarily formed the sample of workers studied to determine the effect of the intervention on food consumption. On average, 10390 workers took their meals at these companies; of them, $1296(12.5 \%)$ participated in the first data collection and $1214(11.7 \%)$ in the second data collection, the samples were independent.

Companies and workers that agreed to participate in the study signed a consent form. The study was approved by the Research Ethics Committee of the Public Health Faculty of São Paulo University. One company dropped out following the initial data collection, so the final sample consisted of fifteen companies in the intervention group and fourteen in the control group.

The present study investigated the availability of fruits, vegetables, fruit and vegetable combinations, energy, protein, carbohydrates, fatty acids and fibre in the menus prepared in workplace cafeterias.

\section{Intervention}

The intervention lasted for 6 months. It was performed in four consecutive stages and addressed aspects of menu planning, food presentation, motivational strategies to encourage the consumption of fruits and vegetables, and a focus on changes in the work environment. The managers of the cafeterias participated in all stages of the intervention.

The first stage of the intervention consisted of producing a manual aimed at the managers of the workplace cafeterias. This manual contained information on the Workers' Food Program and its nutritional guidelines, as well as on the importance of a balanced diet to the health and performance of employees, highlighting the key role of fruits and vegetables. The contents of the manual were presented by the researchers and discussed with the managers of the cafeterias. In the second stage, culinary workshops were run for cafeteria workers and those responsible (cooks and kitchen assistants) for preparing company meals. During the sessions, suggestions for recipes that incorporated fruits and vegetables were presented along with guidance on the presentation and arrangement of culinary preparations.

In the third stage, educational materials were distributed at the workplace cafeteria with messages encouraging fruit and vegetable consumption. Disposable flip-charts with messages encouraging workers to consume fruits and vegetables were placed on all tables in the cafeteria. In addition, labelling information was provided at the point of choice (where the workers chose their food) to indicate healthy options by showing which dish preparations comprised only or mostly fruits and/or vegetables. The last stage involved an educational approach using posters to summarize the main points of the previous stages and promote fruit and vegetable consumption. This stage was extended to include other areas of the company besides the workplace cafeteria.

At the end of the study, the control group also received copies of the educational materials and strategies used in the intervention. 


\section{Data collection}

Company survey

Data collection occurred at two points: at baseline and after the intervention ( 6 months). The main outcome measure was the change in availability of fruits and vegetables (in grams) served to each customer at lunch. Additionally, we assessed the availability of energy (in kilojoules), protein (in percentage of energy), carbohydrates (in percentage of energy), fat (in percentage of energy) and fibre (in grams) in the meals served to workers. Energy and nutrient data were included to verify whether the intervention promoting fruits and vegetables had changed the profile of available nutrients. The lunch menu offered by companies registered in the programme had usually consisted of beans, rice, meat (beef, poultry, fish or eggs), vegetables and a fruit or sweet as dessert, and the workers served the dishes themselves.

Data on fruit, vegetable, energy, protein, carbohydrate, fatty acid and fibre availability were based on three successive days of recording the meals offered to employees prior to the visit by the researcher. Based on the food service managers' reports, all foods that were prepared for serving were listed and their respective quantities per customer per day were recorded (standard portion). The quantities per customer were established by the mean of consumption in each cafeteria. Subsequently, these data were used to determine the availability of fruit and vegetables and to calculate the energy and nutrients per consumer accrued during lunch meals. The TACO chart (Brazilian food composition table) ${ }^{(18)}$, or the US official food composition table version $17^{(19)}$ for the items not present in TACO, was used for conversion from the amount of each food into energy and nutrients.

\section{Individual worker survey}

Data were collected from individual workers at baseline and follow-up ( 6 months); the two samples were independent. To evaluate the consumption of fruits and vegetables in the workplace by workers, participants were asked about the portion consumed at lunch (using as references the utensils used in the distribution of meals in the cafeteria), using the food offered by the company that day to collect data. Subsequently, these data were converted into grams to determine the consumption of fruits and vegetables in the meals.

Information about gender, age and education of workers was also collected to characterize the study sample.

\section{Statistical analysis}

\section{Data from the companies}

A descriptive analysis of the variables of the two study groups (intervention and control) was performed first based on the means and 95\% confidence intervals. Assessment of the intervention's impact included inter-group (intervention $v$. control) differences (at baseline and after the intervention) using Student's $t$ test and intra-group differences using the paired Student's $t$ test. The mean variation between baseline and post-intervention results was ascertained for each group. The comparison of variation between the groups (with a 95\% confidence interval) provided a measure of the effect of the intervention.

In addition, the effect of the intervention adjusted for variations in mean energy intake was calculated by multivariate analysis of variance (MANOVA). Besides adjusting for energy variation, the effects of fruit and vegetable consumption were adjusted at baseline to minimize any effects of inter-group differences prior to the intervention. All analyses were performed with the aid of the STATA Special Edition statistical software package, version $8 \cdot 0$ (Stata Corporation, College Station, TX, USA).

\section{Data from workers}

To evaluate the effect of the intervention on the workers' consumption, the outcome variable used was the consumption of fruits and vegetables (in grams) in the meals offered by the companies. Because the samples at baseline and after the intervention were independent, this analysis was made according to group (intervention and control) and the time of data collection.

To analyse the effect of the intervention, we used linear regression models. In the regression model the outcome variable was the consumption of fruits and vegetables in meals; as an explanatory variable the allocation group (intervention group at baseline, intervention group after follow-up, control group at baseline, control group after follow-up) was used. Thus the regression coefficient expressed the difference in consumption in the intervention group after the intervention, adjusted for consumption of fruits and vegetables in the control group, so that the possible random effects of the intervention would be minimized. Subsequently the model was adjusted for sociodemographic variables (gender, age and education). Variables were included that changed by at least $5 \%$ the magnitude of the regression coefficient for the effect of the intervention on the consumption of fruits and vegetables in the meals offered by companies.

\section{Results}

The majority of the companies participating in the study were from the industrial sector (eighteen companies, nine in each study group) and most (ten in each study group) offered up to 500 meals/d.

At baseline, a total of 1296 individuals (651 in the intervention group and 645 in the control group) were studied. After the intervention, there were 1214 individuals (630 in the intervention group and 584 in the control group; Table 1).

Table 2 shows the mean quantity of fruits, vegetables and nutrients available in each group prior to the intervention, 
Table 1 Characteristics of participants at baseline and after the intervention, according to study group: workers $(n 2510)$ from twenty-nine companies in São Paulo, Brazil

\begin{tabular}{|c|c|c|c|c|c|c|c|c|}
\hline \multirow[b]{3}{*}{ Characteristic } & \multicolumn{4}{|c|}{ Baseline ( $n$ 1296) } & \multicolumn{4}{|c|}{ After intervention ( $n$ 1214) } \\
\hline & \multicolumn{2}{|c|}{ Intervention group } & \multicolumn{2}{|c|}{ Control group } & \multicolumn{2}{|c|}{ Intervention group } & \multicolumn{2}{|c|}{ Control group } \\
\hline & $\%$ & $n$ & $\%$ & $n$ & $\%$ & $n$ & $\%$ & $n$ \\
\hline \multicolumn{9}{|l|}{ Gender } \\
\hline Male & $59 \cdot 6$ & 388 & $61 \cdot 6$ & 397 & $67 \cdot 1$ & 423 & $67 \cdot 3$ & 393 \\
\hline Female & $40 \cdot 4$ & 263 & $38 \cdot 4$ & 248 & $32 \cdot 9$ & 207 & $32 \cdot 7$ & 191 \\
\hline \multicolumn{9}{|l|}{ Education } \\
\hline $1-8$ years & $19 \cdot 4$ & 126 & $20 \cdot 2$ & 130 & $13 \cdot 5$ & 85 & $17 \cdot 5$ & 102 \\
\hline $9-11$ years & $45 \cdot 8$ & 298 & $61 \cdot 9$ & 399 & $40 \cdot 6$ & 256 & $49 \cdot 7$ & 290 \\
\hline$\geq 12$ years & 34.9 & 227 & $18 \cdot 0$ & 116 & $45 \cdot 9$ & 289 & $32 \cdot 9$ & 192 \\
\hline \multicolumn{9}{|l|}{ Age } \\
\hline 18-29 years & $29 \cdot 5$ & 192 & $32 \cdot 1$ & 207 & $28 \cdot 1$ & 177 & $34 \cdot 6$ & 202 \\
\hline 30-39 years & $29 \cdot 2$ & 190 & $31 \cdot 3$ & 202 & $30 \cdot 5$ & 192 & $27 \cdot 4$ & 160 \\
\hline $40-49$ years & $26 \cdot 9$ & 175 & $26 \cdot 7$ & 172 & $26 \cdot 2$ & 165 & $26 \cdot 2$ & 153 \\
\hline$\geq 50$ years & $14 \cdot 4$ & 94 & $9 \cdot 9$ & 64 & $15 \cdot 2$ & 96 & $11 \cdot 8$ & 69 \\
\hline Total & $50 \cdot 2$ & 651 & $49 \cdot 8$ & 645 & $51 \cdot 9$ & 630 & $48 \cdot 1$ & 584 \\
\hline
\end{tabular}

Table 2 Distribution of energy, nutrients, fruits and vegetables offered for lunch at baseline, according to study group: twenty-nine companies in São Paulo, Brazil

\begin{tabular}{|c|c|c|c|c|}
\hline \multirow[b]{2}{*}{ Food/nutrient } & \multicolumn{2}{|c|}{ Intervention group } & \multicolumn{2}{|c|}{ Control group } \\
\hline & Mean & $95 \% \mathrm{Cl}$ & Mean & $95 \% \mathrm{Cl}$ \\
\hline Fruits (g) & $78 \cdot 46^{*}$ & $51 \cdot 40,105 \cdot 55$ & $51 \cdot 39$ & $24 \cdot 88,78 \cdot 09$ \\
\hline Vegetables (g) & $163 \cdot 61$ & $139 \cdot 74,187 \cdot 47$ & $145 \cdot 52$ & $126 \cdot 72,164 \cdot 32$ \\
\hline $\mathrm{F} \& \mathrm{~V}(\mathrm{~g})$ & $242 \cdot 08$ & $209 \cdot 13,275 \cdot 02$ & $196 \cdot 91$ & $157 \cdot 20,236 \cdot 62$ \\
\hline Energy (kJ) & $5816 \cdot 64$ & $5091 \cdot 72,6541 \cdot 56$ & $5595 \cdot 85$ & $4896 \cdot 12,6295 \cdot 58$ \\
\hline Protein (\%E) & $17 \cdot 73$ & $15 \cdot 69,19 \cdot 78$ & $17 \cdot 75$ & $15 \cdot 74,19 \cdot 75$ \\
\hline Carbohydrate (\%E) & $46 \cdot 88$ & $43 \cdot 87,49 \cdot 88$ & $51 \cdot 07$ & $47 \cdot 00,55 \cdot 13$ \\
\hline Fat $(\% \mathrm{E})$ & $35 \cdot 39^{*}$ & $32 \cdot 35,38 \cdot 42$ & $31 \cdot 19$ & $28 \cdot 13,34 \cdot 24$ \\
\hline Fibre $(\mathrm{g})$ & $13 \cdot 69$ & $12 \cdot 06,15 \cdot 32$ & $12 \cdot 33$ & $10 \cdot 86,13 \cdot 79$ \\
\hline
\end{tabular}

$\mathrm{F} \& \mathrm{~V}$, fruits and vegetables, \%E, percentage of energy.

*Mean values were significantly different from those of the control group (Student's $t$ test): $P<0.05$.

Table 3 Temporal variation in the fruits, vegetables, energy and nutrients offered for lunch after the intervention, according to study group: twenty-nine companies in São Paulo, Brazil

\begin{tabular}{|c|c|c|c|c|c|c|c|c|}
\hline \multirow[b]{2}{*}{ Food/nutrient } & \multicolumn{2}{|c|}{ Intervention group } & \multicolumn{2}{|c|}{ Control group } & \multicolumn{2}{|r|}{ Effect } & \multicolumn{2}{|c|}{ Adjusted effect +} \\
\hline & Mean & $95 \% \mathrm{Cl}$ & Mean & $95 \% \mathrm{Cl}$ & Mean & $95 \% \mathrm{Cl}$ & Mean & $95 \% \mathrm{Cl}$ \\
\hline Fruits (g) & $17 \cdot 29$ & $-10 \cdot 23,44 \cdot 81$ & $20 \cdot 50+$ & $6 \cdot 85,34 \cdot 14$ & $-3 \cdot 20$ & $-33 \cdot 22,26 \cdot 81$ & $-1 \cdot 77$ & $-32 \cdot 43,35 \cdot 97$ \\
\hline Vegetables (g) & $33 \cdot 27^{\star}$ & $5 \cdot 75,60 \cdot 78$ & $-17 \cdot 50 t$ & $-32 \cdot 22,-2 \cdot 77$ & $50 \cdot 76$ & $20 \cdot 33,81 \cdot 20$ & $50 \cdot 79$ & $17 \cdot 71,83 \cdot 89$ \\
\hline$F \& V(g)$ & $43 \cdot 69^{*}$ & $9 \cdot 71,77 \cdot 67$ & 0.50 & $-17 \cdot 82,18 \cdot 81$ & $43 \cdot 19$ & $55 \cdot 56,80 \cdot 83$ & $49 \cdot 05$ & $8 \cdot 38,89 \cdot 71$ \\
\hline Energy (kJ) & $-64 \cdot 85$ & $-502 \cdot 29,372 \cdot 63$ & $362 \cdot 13$ & $-285 \cdot 27,1009 \cdot 52$ & $-426 \cdot 94$ & $-1161 \cdot 81,307 \cdot 94$ & - & - \\
\hline Protein (\%E) & $0 \cdot 37$ & $-1 \cdot 94,2 \cdot 68$ & $1 \cdot 46$ & $-0.46,3.38$ & $-1 \cdot 09$ & $-3 \cdot 98,1 \cdot 80$ & $-0 \cdot 76$ & $-3 \cdot 72,2 \cdot 21$ \\
\hline Carbohydrate (\%E) & $5 \cdot 73$ & $-0 \cdot 84,12 \cdot 30$ & $4 \cdot 24$ & $-2 \cdot 69,11 \cdot 18$ & 1.49 & $-7 \cdot 61,10 \cdot 58$ & $5 \cdot 17$ & $-1 \cdot 66,12 \cdot 00$ \\
\hline Fat $(\%)$ & $-5 \cdot 10^{*}$ & $-9.31,-0.88$ & $1 \cdot 89$ & $-4 \cdot 70,8 \cdot 47$ & $-6 \cdot 98$ & $-14 \cdot 32,0 \cdot 35$ & $-4 \cdot 27$ & $-10 \cdot 20,1 \cdot 66$ \\
\hline Fibre $(\mathrm{g})$ & $1 \cdot 96^{\star}$ & $0 \cdot 27,3 \cdot 64$ & $1 \cdot 15$ & $-0.25,2 \cdot 56$ & $0 \cdot 80$ & $-1 \cdot 30,2 \cdot 91$ & $1 \cdot 35$ & $-0.62,3.33$ \\
\hline
\end{tabular}

$\mathrm{F} \& \mathrm{~V}$, fruits and vegetables, \%E, percentage of energy.

*Mean values were significantly different from those at baseline (paired Student's $t$ test): $P<0.05$.

tFor fruits, vegetables and F\&V, differences were adjusted for the change of total energy and the presence of F\&V at baseline; for nutrients, differences were adjusted for the change of total energy.

demonstrating that the groups differed only in the distribution of total fruit and percentage of energy from fat.

Table 3 shows the increased availability of fruits and vegetables among companies in the intervention group over the 6-month study period. After adjustment, the intervention group offered about $49 \mathrm{~g}$ more fruits and vegetables following the intervention compared with the control group. The intervention group also reduced the level of total fat and increased fibre availability; this finding demonstrates that an intervention, even when focused on increasing fruit and vegetable consumption, can also lead to other beneficial changes in the nutrient 
Table 4 Effect of the intervention on the consumption of fruits and vegetables by workers from twenty-nine companies in São Paulo, Brazil

\begin{tabular}{|c|c|c|c|c|c|c|c|c|}
\hline \multirow[b]{3}{*}{ Group } & \multicolumn{4}{|c|}{ Consumption of $F \& V$ in companies $(\mathrm{g} / \mathrm{d})$} & & & & \\
\hline & \multicolumn{2}{|c|}{ Baseline } & \multicolumn{2}{|c|}{ After intervention } & \multicolumn{2}{|c|}{ Effect of interventiont } & \multicolumn{2}{|c|}{ Adjusted effect of intervention $\ddagger$} \\
\hline & Mean & $95 \% \mathrm{Cl}$ & Mean & $95 \% \mathrm{Cl}$ & $\beta$ & $95 \% \mathrm{Cl}$ & $\beta$ & $95 \% \mathrm{Cl}$ \\
\hline Control & $102 \cdot 10$ & $94 \cdot 89,109 \cdot 31$ & $109 \cdot 65$ & $103 \cdot 28,116 \cdot 02$ & - & & - & \\
\hline Intervention & $104 \cdot 85$ & $98 \cdot 71,110 \cdot 99$ & 123.03 & $117 \cdot 14,128.93$ & $13 \cdot 21$ & $4 \cdot 20,22 \cdot 22$ & $11 \cdot 75$ & $2 \cdot 73,20 \cdot 77$ \\
\hline
\end{tabular}

F\&V, fruits and vegetables.

tEffect of the intervention obtained in the linear regression model for the difference in the intervention group, adjusted for consumption of $F \& V$ in the control group. $\ddagger$ Effect of the intervention obtained in the linear regression model for the difference in the intervention group, adjusted for consumption of $F \& V$ in the control group and sociodemographic characteristics of the workers (sex, education and age).

composition of meals. For the intervention-group companies, the mean quantity of fruits and vegetables available per meal was $285 \mathrm{~g}$. The control group, however, had a mean value of $197 \mathrm{~g}$, which was practically equal to the baseline level.

After the intervention, there was an increase in the consumption of fruits and vegetables by workers in the intervention group (from $104 \cdot 85$ to $123.03 \mathrm{~g}$ ). The effect of the intervention, determined by linear regression models, showed that there was an increase of $13 \cdot 21 \mathrm{~g}$ in the consumption of fruits and vegetables in the intervention group, controlling for consumption in the control group. After adjustment for sociodemographic characteristics, the effect of the intervention on the consumption of these foods remained significant (Table 4).

\section{Discussion}

The proposed ecological intervention proved to have a positive effect on fruit and vegetable intake in workplace cafeterias, increasing availability in lunch meals by an average of $49 \mathrm{~g}$ compared with the control group. The effect on consumption of fruits and vegetables in meals by the workers, although lower, was also significant, representing an average increase by about $11 \mathrm{~g}$. These results demonstrate that actions focused on the work environment can be effective in increasing the consumption of healthy foods in the workplace.

Strategies promoting fruits and vegetables in the workplace have shown positive results ${ }^{(11,20,21)}$. To date, the majority of strategies have been aimed at changing individual behaviour ${ }^{(22)}$. In recent years, some studies have focused on changes to the environment and have shown great potential for promoting healthy nutrition ${ }^{(23)}$.

Our intervention used an environmental approach to promote healthy choices while also demonstrating a positive impact and cost-effectiveness ${ }^{(24)}$. There were a number of important factors that led to the success of our intervention: changes were made in the cafeteria to increase the availability of healthy food options, the healthy foods were advertised, and the employees were involved in the planning and management of meals ${ }^{(25)}$. Thus the present study not only used strategies for intervention that proved effective in other studies (i.e. labelling) but also involved the managers of the cafeterias.

A study similar to the present investigation was carried out in five companies in Denmark and reported a significant increase in fruit and vegetable intake after applying strategies targeting the managers and employees of work-site canteens. The study also showed that the effects of the intervention persisted for 4 months after the intervention end-point ${ }^{(15)}$.

Glanz and Hoelscher reviewed six different intervention strategies for promoting fruit and vegetable consumption (increasing availability and access, reducing prices, providing information on healthy nutrition and communication strategies) and showed that approaches combining several strategies were particularly effective ${ }^{(26)}$.

Another key finding was the importance of engaging workplace cafeteria managers and staff to achieve successful outcomes for work-site intervention strategies. According to Steenhuis et al., who interviewed workplace cafeteria managers about the viability of adopting educational and environmental programmes to promote a healthy diet, managers deemed the promotion of healthy food habits important but emphasized that strategies should be voluntary and unobstructive. The managers also stated that any changes introduced must not cause a delay in the production and serving of meals ${ }^{(12)}$. In our intervention, each stage was discussed and agreed upon with the managers of the cafeterias.

The intervention had a stronger effect on the availability of vegetables; this result is due to the importance of this food group in the composition of menus, as salads and side dishes. Other studies also observed that the inclusion of vegetables is easier with warm preparations such as a side dish ${ }^{(15,27)}$. Emphasizing that as a strategy of intervention, in the present study the culinary workshop's special focus was given to the preparation and presentation of vegetables on the menus offered.

The construct of indicators used to assess the impact of the intervention model based on ecological food consumption of workers is complex. FFQ are not sufficiently sensitive to assess small changes in quantity and in short periods of time ${ }^{(28)}$. In the present study, the consumption of fruits and vegetables in meals offered in companies was evaluated. This choice was based on an ecological 
model of intervention and on the assumption that its influence should express itself on food consumption in the modified environment, where the cafeterias of the companies were studied.

The results showed a slight but positive increase in the workers' consumption of fruits and vegetables in the meals offered by the companies. A systematic literature review found that interventions that used individual and ecological strategies for promoting fruits and vegetables had a positive impact, with an increase of between 3 and $16 \%$ in the consumption of these foods in controlled studies ${ }^{(29)}$. The present study identified an approximately 15\% increase, within the range expected for interventions in the workplace.

The main limitation of the present study was the absence of indicators to assess the intervention process and the motivation of managers to implement the strategies. These indicators are important for understanding the real cause of the changes and the effectiveness of the ecological model ${ }^{(30)}$. Thus, the results of the intervention cannot be compared to identify adherence factors.

An accurate measure of participation is essential for assessment of the true effectiveness and external validity of intervention strategies. In our study, the rate of acceptance to participate in the intervention programme was $40 \%$, a level considered satisfactory. Low adherence of companies to health promotion programmes is common, with participation rates falling as low as $20 \%{ }^{(31)}$.

Workplace environmental strategies are considered a lower-cost option than strategies to change individual behaviours, and they also allow for the creation of a healthy environment that promotes and sustains healthy habits for individuals ${ }^{(32)}$.

The present study is the first of its kind in Brazil. It applied a controlled study design and involved a multicomponent intervention approach focused on the workplace environment. The findings of the study have shown great potential to bring about changes and promote healthy dietary habits.

In conclusion, the intervention was effective, leading to increase in the offer and consumption of fruits and mainly vegetables in the dishes of the meals offered by the studied companies, demonstrating that simple interventions involving company managers are feasible and effective in the promotion of fruit and vegetable intake at the workplace.

\section{Acknowledgements}

The study was supported by National Council for Scientific and Technological Development (CNPq). There was no conflict of interest. D.H.B. contributed to conception, design, analysis, interpretation of the data and elaboration of the paper; F.S. contributed to analysis, interpretation of the data and review of the paper; P.C.J. contributed to conception, design, analysis, interpretation of the data and review of the paper.

\section{References}

1. Van't Veer P, Jansen MCJF, Klerk M et al. (2000) Fruits and vegetables in the prevention of cancer and cardiovascular disease. Public Health Nutr 3, 103-107.

2. Dauchet P, Amouye P, Hercberg S et al. (2006) Fruit and vegetable consumption and risk of coronary heart disease: a meta-analysis of cohort studies. J Nutr 136, 2588-2593.

3. World Health Organization (2004) Fruit and Vegetables For Health. Report of a Joint FAO/WHO Workshop, 1-3 September 2004, Kobe, Japan. Geneva: WHO.

4. Van Duyn MAS \& Pivonka E (2000) Overview of the health benefits of fruit and vegetable consumption for the dietetics professional: selected literature. J Am Diet Assoc 100, 1511-1521.

5. Jaime PC \& Monteiro CA (2005) Fruit and vegetable intake by Brazilian adults. Cad Saude Publica 21, Suppl. 1, S19-S24.

6. Glanz K, Patterson RE, Kristal AR et al. (1998) Impact of work site health promotion on stages of dietary change: the Working Well Trial. Health Educ Behav 25, 448-463.

7. Chu C, Breucker G, Harris N et al. (2000) Health promoting workplaces - international settings development. Health Promot Int 15, 155-167.

8. Sorensen G, Morris D, Hunt MK et al. (1992) Worksite nutrition intervention and employee dietary habits: the Treatwell Program. Am J Public Health 82, 877-880.

9. Hebert JR, Harris DR, Sorenson G et al. (1993) A work-site nutrition intervention: its effects on the consumption of cancer-related nutrients. Am J Public Health 83, 391-394.

10. Sorensen G, Thompson B, Glanz K et al. (1996) Work sitebased cancer prevention: primary results from the Working Well Trial. Am J Public Health 86, 939-947.

11. Beresford SA, Thompson B, Feng Z et al. (2001) Seattle 5 a Day worksite program to increase fruit and vegetable consumption. Prev Med 32, 230-238.

12. Steenhuis IH, Van Assema P \& Glanz K (2001) Strengthening environmental and educational nutrition programmes in worksite cafeterias and supermarkets in the Netherlands. Health Promot Int 16, 21-33.

13. Sorensen G, Stoddard AM, Montange AD et al. (2002) A comprehensive worksite cancer prevention intervention; behavior change results from a randomized controlled trial (United States). Cancer Causes Control 13, 493-502.

14. McLeroy KR, Bibeau D, Steckler A et al. (1988) An ecological perspective on health promotion programs. Health Educ Q 15, 351-377.

15. Lassen A, Thorsen AV, Trolle E et al. (2004) Successful strategies to increase the consumption of fruits and vegetables: results from the Danish ' 6 a day' Work-site Canteen Model Study. Public Health Nutr 7, 263-270.

16. Pomerleau J, Lock K, Knai C et al. (2005) Interventions designed to increase adult fruit and vegetable intake can be effective: a systematic review of the literature. J Nutr $\mathbf{1 3 5}$, 2486-2495.

17. Sávio KEO, Costa THM da, Miazaki E et al. (2005) Avaliação do almoço servido a participantes do programa de alimentação do trabalhador. Rev Saude Publica 39, 148-155.

18. Núcleo de Estudos e Pesquisas em Alimentação/Universidade Estadual de Campinas (2006) Tabela Brasileira de Composição de Alimentos - TACO: versão 2. Campinas, SP: NEPA/UNICAMP.

19. US Department of Agriculture (2004) USDA Food Search for Windows, version 1.0, database version Standard Reference Release SR17. http://www.nal.usda.gov/fnic/ foodcomp (accessed March 2008).

20. Buller DB, Morill C, Taren D et al. (1999) Randomized trial testing the effect of peer education at increasing fruit and vegetable intake. J Natl Cancer Inst 91, 1491-1500. 
21. Sorensen G, Stoddard A, Peterson K et al. (1999) Increasing fruit and vegetable consumption through worksites and families in the Treatwell 5-a-Day Study. Am J Public Health 89, 54-60.

22. Harden A, Peersman G, Oliver S et al. (1999) A systematic review of the effectiveness of health promotion interventions in the workplace. Occup Med 49, 540-548.

23. Story M, Kaphingst KM, Robinson-O'Brien R et al. (2008) Creating healthy food and eating environments: policy and environmental approaches. Annu Rev Public Health 29, 253-272.

24. Anderson LM, Quinn TA, Glanz K et al. (2009) The effectiveness of worksite nutrition and physical activity interventions for controlling employee overweight and obesity: a systematic review. Am J Prev Med 37, 340-357.

25. Steyn NP, Parker W, Lambert EV et al. (2009) Nutrition interventions in the workplace: evidence of best practice. $S$ Afr J Clin Nutr 22, 111-117.

26. Jeffery RW, French SA, Raether C et al. (1994) An environmental intervention to increase fruit and salad purchases in a cafeteria. Prev Med 23, 788-792.
27. Glanz K \& Hoelscher D (2004) Increasing fruit and vegetable intake by changing environments, policy and pricing: restaurant-based research, strategies, and recommendations. Prev Med 39, Suppl. 2, S88-S93.

28. Mhurchu CN, Aston LM \& Jebb SA (2010) Effects of worksite health promotion interventions on employee diets: a systematic review. BMC Public Health 10, 6.

29. Beresford SAA, Shannon J, McLerran D et al. (2000) Seattle 5-a-Day work-site project: process evaluation. Health Educ Behav 27, 213-222.

30. Brug J, Oenema A \& Ferreira I (2005) Theory, evidence and intervention mapping to improve behaviour, nutrition and physical activity interventions. Int J Behav Nutr Phys Act 2, 2.

31. Kwak L, Kremers SPJ, Van Baak MA et al. (2006) Participation rates in worksite-based intervention studies: health promotion context as a crucial quality criterion. Health Promot Int 21, 66-69.

32. Sorensen G, Linnan L \& Hunt K (2004) Worksite-based research and initiatives to increase fruit and vegetable consumption. Prev Med 39, Suppl., S94-S100. 